\title{
High-intensity focused ultrasound for noninvasive body contouring: current perspectives
}

This article was published in the following Dove Press journal:

Research and Reports in Focused Ultrasound

29 January 2015

Number of times this article has been viewed

\author{
Michael Frank \\ Nazanin Saedi \\ Department of Dermatology and \\ Cutaneous Biology, Thomas Jefferson \\ University, Philadelphia, \\ PA, USA
}

\begin{abstract}
Noninvasive devices for fat reduction have become increasingly popular over the past decade. High-intensity focused ultrasound (HIFU), already in use for nearly half a century for the noninvasive treatment of tumors, has only recently been evaluated as a method for the selective ablation of adipose tissue. HIFU works by focusing high-intensity ultrasonic waves at the level of the subcutaneous adipose tissue, causing focal coagulative necrosis with contraction and thickening of adjacent collagen bundles while sparing the overlying tissue. Several studies reveal the safety and efficacy of HIFU for fat reduction in the abdomen and flanks. These studies show a consistent reduction in the abdominal circumference of at least $2 \mathrm{~cm}$ after a single treatment. Adverse events are limited to mild, transient procedural and postprocedural discomfort, erythema, bruising, and edema. HIFU is a safe and effective method for focal fat reduction.
\end{abstract}

Keywords: body sculpting, HIFU, lipoplasty, high-intensity focused ultrasonography

\section{Introduction}

Mankind has been pursuing body contouring since at least the 16th century by way of the corset. Today, the technology has changed but the goal remains the same: to optimize the smoothness, definition, or silhouette of the human physique, particularly the torso. ${ }^{1}$ Lipoplasty is the fourth most popular cosmetic surgical procedure performed in the US. ${ }^{2}$ However, it is expensive, invasive, and associated with significant downtime, morbidity, and mortality. ${ }^{3,4}$ For this reason, there is a strong demand for noninvasive body sculpting technologies such as cryolipolysis, radiofrequency, external low-level laser therapy, injection lipolysis, low-frequency nonthermal ultrasound, and high-intensity focused ultrasound (HIFU). As one of the newest of these technologies, HIFU will be the focus of this article.

HIFU is a method of noninvasive tissue heating and ablation currently used for treating a variety of disorders, including shock wave lithotripsy, uterine fibroids, and solid organ tumors. ${ }^{5}$ It reduces focal adiposity by delivering high-energy ultrasonic waves across the skin at a low intensity before sharply focusing them at the level of the subcutaneous adipose tissue (SAT). At the skin surface, the intensity of the waves is low enough to avoid tissue damage. However, at the level of the SAT, the waves are focused to a high enough intensity to induce focal coagulative necrosis. This fat ablation is achieved by two mechanisms: hyperthermia and inertial cavitation. ${ }^{5}$ HIFU causes molecular vibration of the targeted adipocytes and subsequent rapid heating to temperatures exceeding the upper limit of protein denaturation $\left(60^{\circ} \mathrm{C}-65^{\circ} \mathrm{C}\right)$, resulting in coagulative necrosis. The mechanical ultrasound wave also travels through the adipocytes, creating cycles of increased and reduced pressure, which draw gas out of
Correspondence: Michael Frank Department of Dermatology and Cutaneous Biology, Thomas Jefferson University, 833 Chestnut Street, Suite 740, Philadelphia, PA 19107, USA

Tel +I 2159556680

Email michael.frank@jefferson.edu
Research and Reports in Focused Ultrasound 2015:3 I-4

Dovepress

http://dx.doi.org//0.2147/RRFU.S5583| (c) (i) (5) 2015 Frank and Saedi. This work is published by Dove Medical Press Limited, and licensed under Creative Commons Attribution - Non Commercial (unported, v3.0) License. The full terms of the license are available at http:///creativecommons.org/licenses/by-n/3.0\%. Non-commercial uses of the work are permitted without any further permission from Dove Medical Press Limited, provided the work is properly attributed. Permissions beyond the scope of the License are administered by Dove Medical Press Limited. Information on
how to request permission may be found at: http://www.dovepress.com/permissions.php 
solution in the form of bubbles. When these bubbles implode, they release energy, causing further mechanical damage to the targeted adipocytes. ${ }^{6,7}$ Dying adipocytes release chemotactic factors that induce a mild inflammatory response, attracting macrophages that phagocytize and clear the extracellular lipids and cellular debris. ${ }^{8}$ The ultimate result is reduction of the subcutaneous fat layer without damaging the surrounding tissue.

\section{Preclinical studies}

Preclinical studies using HIFU for noninvasively ablating SAT were performed in pigs, a popular model system for obesity research because their SAT, with its lobular organization of fat and collagenous fibrous septae, is analogous to that of humans., ${ }^{9,10}$ Thermocouples demonstrated the focal heating of the SAT with sparing of the surrounding tissue. Histopathology then confirmed the presence of coagulative necrosis confined to the SAT with sparing of the nerves, arterioles, and overlying epidermis and dermis. Contraction and thickening of adjacent collagen bundles were also noted. Extensive blood testing prior to, during, and for 72 hours after the procedure revealed that lipid levels, liver function tests, and urinalysis remained within normal limits. These studies, in addition to HIFU's successful use for over half a century in treating other unrelated conditions, paved the way for human pilot studies.

\section{Pilot studies}

Gadsden et a $1^{11}$ conducted three clinical feasibility and pilot studies evaluating the safety of HIFU for ablating human abdominal adipose tissue. A total of 152 healthy men and women with a body mass index (BMI) $<30 \mathrm{~kg} / \mathrm{m}^{2}$ and an $\mathrm{SAT} \geq 2.0 \mathrm{~cm}$ at the intended treatment site, were treated with total energy doses of 47-331 J/ $\mathrm{cm}^{2}$. Post-treatment ultrasound confirmed that the effects were limited to the targeted SAT layers. Histopathology showed well-demarcated disruption of adipocytes that was confined to the targeted SAT layers with no evidence of thermal injury to the dermis or epidermis. It also showed that clearance of extracellular lipids was performed by macrophages and takes up to 14 weeks. Lipid panels, liver enzymes, clinical chemistries, and creatine phosphokinases were monitored for up to 3 months after treatment without any clinically significant deviations from baseline. Adverse events included treatment discomfort, edema, erythema, dysesthesia, and ecchymosis. All the adverse events resolved by 12 weeks.

Fatemi ${ }^{8}$ treated the anterior abdomen and flanks of 282 patients with unspecified BMIs and an SAT $\geq 2.6 \mathrm{~cm}$ at each treatment site with at least two passes of varying energy. Waist circumference decreased by an average of $4.7 \mathrm{~cm}$. A post hoc analysis showed that patients treated with $>133 \mathrm{~J} / \mathrm{cm}^{2}$ achieved an average waist reduction of $4.6 \mathrm{~cm}$, which was not significantly greater than the $4.2 \mathrm{~cm}$ reduction achieved with $126 \mathrm{~J} / \mathrm{cm}^{2}$ or less. A subgroup of these patients subsequently had abdominoplasties, and the histopathology of the treated areas showed disruption of adipocytes with collapse of their cell membranes and disruption along with denaturation of septal and collagen fibers. Thirty-eight patients (13.5\%) reported one or more adverse event. Ten reported pain, three had hard lumps, and 28 had ecchymoses, all of which resolved spontaneously within 4 weeks. Six had edema, which resolved within 12 weeks. Five reported significant pain during treatment, which resolved upon treatment completion. There was no evidence to suggest that these adverse events were dose related.

\section{Further studies}

Fatemi and Kane ${ }^{12}$ published a retrospective review of 85 healthy men and women with BMIs $<30 \mathrm{~kg} / \mathrm{m}^{2}$ and an SAT $\geq 2.1 \mathrm{~cm}$ at each treatment site treated with a mean energy level of $134.8 \mathrm{~J} / \mathrm{cm}^{2}$ over two passes on their anterior abdomen and flanks. The mean decrease in waist circumference was $4.6 \mathrm{~cm}$ after 3 months. Serum cholesterol, triglycerides, high- and low-density lipoproteins, and liver enzymes were measured in ten patients for 16 weeks after the procedure without any statistically significant changes. Ten patients $(11.8 \%)$ reported adverse events. These included pain during the procedure $(n=1)$, hard lumps $(n=2)$, prolonged tenderness $(n=3)$, and ecchymoses $(n=3)$, all of which resolved within 4 weeks. Edema was noted in one patient and resolved within 12 weeks.

Shek et $\mathrm{al}^{13}$ reported a study of 12 healthy men and women with BMIs not more than $30 \mathrm{~kg} / \mathrm{m}^{2}$ and SAT $\geq 2.5 \mathrm{~cm}$ at the treatment site, whose anterior abdomens were treated with an average of $161 \mathrm{~J} / \mathrm{cm}^{2}$. At 12 weeks there was an average decrease in waist circumference of $2.1 \mathrm{~cm}$. Higher fluence significantly correlated with a greater decrease in waist circumference. Average discomfort during the procedure, rated on a scale of $0-10$, was 5.7. Using a lower fluence with a greater number of passes improved comfort during the procedure.

Shalom et $\mathrm{al}^{14}$ published a single-blind pilot study in which six healthy adults with an average BMI of $25.5 \mathrm{~kg} / \mathrm{m}^{2}$ and an $\mathrm{SAT} \geq 1.2 \mathrm{~cm}$ at the treatment site, had one side of their abdomen treated with HIFU and the other side with placebo. These patients were followed for 28 days after treatment 
to monitor for efficacy and laboratory abnormalities before undergoing abdominoplasty. There was no statistically significant increase in lipids, liver enzymes, or clinical chemistry after the procedure. During abdominoplasty, treated skin was sent for histopathology, which showed fat necrosis with infiltration of lymphocytes and macrophages without adjacent tissue damage. No anesthetics were given prior to the procedure, and a visual analog scale ranging from 0 to 7 was used to rate the discomfort experienced during the procedure. Average discomfort was rated 3.5 out of 7 . Four patients (67\%) developed small areas of mild erythema or abrasion, which spontaneously resolved within hours to days.

Jewell et al ${ }^{1,15}$ performed a sham-controlled, randomized trial to evaluate the safety, tolerability, and effectiveness of HIFU for body contouring. A total of 168 patients with a $\mathrm{BMI} \leq 30 \mathrm{~kg} / \mathrm{m}^{2}$ and an SAT $\geq 2.5 \mathrm{~cm}$ at the treatment sites were randomly assigned to treatment of their anterior abdomen and flanks with three passes of $47 \mathrm{~J} / \mathrm{cm}^{2}\left(141 \mathrm{~J} / \mathrm{cm}^{2}\right.$ total), $59 \mathrm{~J} / \mathrm{cm}^{2}$ (177 J/ $\mathrm{cm}^{2}$ total), or $0 \mathrm{~J} / \mathrm{cm}^{2}\left(0 \mathrm{~J} / \mathrm{cm}^{2}\right.$ total). Patients who received $141 \mathrm{~J} / \mathrm{cm}^{2}$ showed an average reduction in waist circumference of $2.1 \mathrm{~cm} 12$ weeks after treatment. Patients treated with $177 \mathrm{~J} / \mathrm{cm}^{2}$ had an average reduction of $2.52 \mathrm{~cm}$. Patients in the control group averaged a $1.21 \mathrm{~cm}$ reduction. Lipid profiles, markers of inflammation, coagulation, liver function, and renal function were monitored before treatment, 1 hour after treatment, and at 1 week, 4 weeks, 8 weeks, 12 weeks, and 24 weeks after treatment. No clinical laboratory abnormalities were found. A $100 \mathrm{~mm}$ visual analog scale was used to rate discomfort during and after treatment (ie, $0-4$, no pain; 5-44, mild pain; $45-74$, moderate pain; and 75-100, severe pain). Of the 122 patients in the treatment group, $90 \%$ experienced discomfort during the procedure, with more discomfort ( $32.5 \mathrm{~mm}$ versus $23.5 \mathrm{~mm}$ ) being reported in those treated with $59 \mathrm{~J} / \mathrm{cm}^{2}$ versus $47 \mathrm{~J} / \mathrm{cm}^{2}$. However, both still qualified as "mild" discomfort. Fifty-seven percent of patients reported postprocedural discomfort, which completely resolved within 7-10 days. Sixty-six percent experienced ecchymosis, which resolved within 12-14 days. Nine percent experienced swelling, which resolved in 13-16 days. No severe adverse events were reported.

Solish et al ${ }^{16}$ studied the effects of different fluences on fat reduction using HIFU in a randomized, single-blinded postmarketing study. Forty-seven patients with BMIs $\leq 30$ $\mathrm{kg} / \mathrm{m}^{2}$ and an SAT $\geq 2.6 \mathrm{~cm}$ at their treatment sites, had their anterior abdomens treated with three passes of $47 \mathrm{~J} / \mathrm{cm}^{2}$, $52 \mathrm{~J} / \mathrm{cm}^{2}$, or $59 \mathrm{~J} / \mathrm{cm}^{2}$ for a total of $141 \mathrm{~J} / \mathrm{cm}^{2}, 156, \mathrm{~J} / \mathrm{cm}^{2}$, or $177 \mathrm{~J} / \mathrm{cm}^{2}$, respectively. At the 1-week follow-up visit, there was an average abdominal circumference reduction of
$2.51 \mathrm{~cm}$, with no statistically significant difference between the different fluences and the amount of reduction in circumference. A $100 \mathrm{~mm}$ visual analog scale was used to rate discomfort during treatment. The average level of discomfort for all three treatment groups qualified as "mild", with higher fluences being associated with higher mean scores of discomfort, but not to a statistically significant level. Of note, $90 \%$ of patients received analgesic medication ( $5 \mathrm{mg}$ oxycodone $/ 325$ $\mathrm{mg}$ acetaminophen $\times 2$ or $300 \mathrm{mg}$ acetaminophen $/ 30 \mathrm{mg}$ codeine) prior to treatment. The majority of patients reported mild or transient bruising or erythema at the treatment site.

Table 1 demonstrates the average decrease in waist circumference seen 12 weeks after treatment with varying amounts of total energy.

\section{Limitations}

Although promising, HIFU does not replace the importance of a healthy diet and lifestyle, nor is it an effective weight loss tool. ${ }^{1,13,15,16}$ As with lipoplasty, HIFU is unlikely to reduce one's risk for cardiovascular or metabolic disease, as it does not target visceral fat. ${ }^{17,18}$ So although this procedure may help patients look and feel better, the results are entirely cosmetic. Also of note, almost all of the HIFU studies were carried out in patients with BMIs $\leq 30 \mathrm{~kg} / \mathrm{m}^{2}$ and with modest results. HIFU is a good option for treating "trouble spots" in nonobese patients, but lipoplasty remains the treatment of choice for large volume contouring in obese patients. Although current studies demonstrate that HIFU is safe with only minimal, transient adverse effects, there is one case report of a patient developing acute pancreatitis 24 hours after HIFU for reduction of focal adiposity of the flanks and lumbar zone. ${ }^{19}$ It is unlikely that HIFU played a role in this man developing acute pancreatitis, given the absence of hypertriglyceridemia and in the setting of him having several established risk factors, but this highlights the need for

Table I Total energy and mean decrease in waist circumference after 12 weeks

\begin{tabular}{llll}
\hline Reference & $\begin{array}{l}\text { Number of } \\
\text { patients } \\
\text { treated }\end{array}$ & $\begin{array}{l}\text { Total } \\
\text { energy } \\
\left(\mathbf{J} / \mathbf{c m}^{2}\right)\end{array}$ & $\begin{array}{l}\text { Average waist } \\
\text { circumference decrease } \\
\text { after I2 weeks } \mathbf{( c m})\end{array}$ \\
\hline 8 & 282 & $\geq 140$ & 4.7 \\
12 & 85 & 134.7 & 4.6 \\
13 & 12 & $16 \mid$ & 2.1 \\
1 & 58 & 0 & 1.21 \\
& 59 & 141 & 2.1 \\
& 63 & 177 & 2.5 \\
16 & 14 & 141 & 2.3 \\
& 16 & 156 & 2.7 \\
& 15 & 177 & 2.5 \\
\hline
\end{tabular}


long-term safety data for this procedure. Similarly, the lack of long-term follow-up studies places the permanency and long-term cosmetic outcome of this procedure in question.

\section{Conclusion}

Still in its infancy, HIFU has great potential for noninvasive body sculpting by targeting focal "problem areas", with the added benefit of skin tightening. Treatments take less than an hour with minimal downtime or adverse effects. Results are noticeable after a single treatment. HIFU is a promising new modality that we have only begun to start exploring.

\section{Disclosure}

The authors report no conflicts of interest in this work.

\section{References}

1. Jewell ML, Baxter RA, Cox SE, et al. Randomized sham-controlled trial to evaluate the safety and effectiveness of a high-intensity focused ultrasound device for noninvasive body sculpting. Plast Reconstr Surg. 2011;128(1):253-262.

2. The American Society of Plastic Surgeons: National Clearinghouse of Plastic Surgery Procedural Statistics. 2013 Plastic Surgery Statistics Report. Available at: http://www.plasticsurgery.org/news/plasticsurgery-statistics/2013.html. Accessed July 3, 2014.

3. Hughes CE III. Reduction of lipoplasty risks and mortality: an ASAPS survey. Aesthet Surg J. 2001;21:120-127.

4. Jewell M. Commentary. Aesthet Surg J. 2001;21:125-127.

5. Kennedy JE. High-intensity focused ultrasound in the treatment of solid tumours. Nat Rev Cancer. 2005;5(4):321-327.

6. Haar GT, Coussios C. High intensity focused ultrasound: physical principles and devices. Int J Hyperthermia. 2007;23(2):89-104.

7. Tadisina KK, Patel MN, Chopra K. High-intensity focused ultrasound in aesthetic plastic surgery. Eplasty. 2013;13:ic56.
8. Fatemi A. High-intensity focused ultrasound effectively reduces adipose tissue. Semin Cutan Med Surg. 2009;28:257-262.

9. Jewell ML, Desilets C, Smoller BR. Evaluation of a novel high-intensity focused ultrasound device: preclinical studies in a porcine model. Aesthet Surg J. 2011;31(4):429-434.

10. Vardaxis N, Brans T, Boon M, Kreis R, Marres L. Confocal laser scanning microscopy of porcine skin: implications for human wound healing studies. J Anat. 1997;190(Pt 4):601-611.

11. Gadsden E, Aquilar MT, Smoller BR, Jewell ML. Evaluation of a novel high-intensity focused ultrasound device for ablating subcutaneous adipose tissue for noninvasive body contouring: safety studies in human volunteers. Aesthet Surg J. 2011;31(4):401-410.

12. Fatemi A, Kane MA. High-intensity focused ultrasound effectively reduces waist circumference by ablating adipose tissue from the abdomen and flanks: a retrospective case series. Aesthetic Plast Surg. 2010;34(5):577-582.

13. Shek SYN, Yeung CHK, Chan JCY, Chan HHL. Efficacy of highintensity focused ultrasonography for noninvasive body sculpting in Chinese patients. Lasers Surg Med. 2014;46(4):263-269.

14. Shalom A, Wiser I, Brawer S, Azhari H. Safety and tolerability of a focused ultrasound device for treatment of adipose tissue in subjects undergoing abdominoplasty: a placebo-control pilot study. Dermatol Surg. 2013;39(5):744-751.

15. Jewell ML, Weiss RA, Baxter RA, et al. Safety and tolerability of high-intensity focused ultrasonography for noninvasive body sculpting: 24-week data from a randomized, sham-controlled study. Aesthet Surg J. 2012;32(7):868-876.

16. Solish N, Lin X, Axford-Gatley RA, Strangman NM, Kane M. A randomized, single-blind, postmarketing study of multiple energy levels of high-intensity focused ultrasound for noninvasive body sculpting. Derm Surg. 2012;38(1):58-67.

17. Danilla S, Longton C, Valenzuela K, et al. Suction-assisted lipectomy fails to improve cardiovascular metabolic markers of disease: a metaanalysis. J Plast Reconstr Aesthet Surg. 2013;66(11):1557-1563.

18. Benatti FB, Lira FS, Oyama LM, do Nascimento CM, Lancha AH Jr. Strategies for reducing body fat mass: effects of liposuction and exercise on cardiovascular risk factors and adiposity. Diabetes Metab Syndr Obes. 2011;4:141-154.

19. Grassi DG, Gavier B, Trucco J, Bana MT. Acute pancreatitis after highintensity focused ultrasonography for body sculpting. Ann Intern Med. 2014;160(1):71-72.
Research and Reports in Focused Ultrasound

\section{Publish your work in this journal}

Research and Reports in Focused Ultrasound is an international, peerreviewed, open access online journal publishing original research, study protocols, reports, editorials, reviews and commentaries on all aspects of focused ultrasound technologies for the treatment of cancer and other diseases. The manuscript management system is completely

\section{Dovepress}

online and includes a very quick and fair peer-review system, which is all easy to use. Visit http://www.dovepress.com/testimonials.php to read real quotes from published authors. 